\title{
50 \\ Disciplining and Screening Top Executives
}

Silvia Dominguez-Martinez

Otto H. Swank

Bauke Visser 


\section{Tinbergen Institute}

The Tinbergen Institute is the institute for economic research of the Erasmus Universiteit Rotterdam, Universiteit van Amsterdam, and Vrije Universiteit Amsterdam.

Tinbergen Institute Amsterdam

Roetersstraat 31

1018 WB Amsterdam

The Netherlands

Tel.: $\quad+31(0) 205513500$

Fax: $\quad+31(0) 205513555$

Tinbergen Institute Rotterdam

Burg. Oudlaan 50

3062 PA Rotterdam

The Netherlands

Tel.: $\quad+31(0) 104088900$

Fax: $\quad+31(0) 104089031$

Most TI discussion papers can be downloaded at http:/ /www.tinbergen.nl. 


\title{
Disciplining and Screening Top Executives*
}

\author{
Silvia Dominguez-Martinez† Otto H. Swank and Bauke Visser \\ Erasmus University Rotterdam and Tinbergen Institute
}

June 2006

\begin{abstract}
Boards of directors face the twin task of disciplining and screening executives. To perform these tasks directors do not have detailed information about executives' behaviour, and only infrequently have information about the success or failure of initiated strategies, reorganizations, mergers etc. We analyse the nature of (implicit) retention contracts boards use to discipline and screen executives. Consistent with empirical observation, we find that executives may become overly active to show their credentials; that the link between bad performance and dismissal is weak; and that boards occasionally dismiss competent executives.
\end{abstract}

Key words: board of directors, turnover, retention contracts, selection, moral hazard, empire building

JEL Classification: G30, G34

\section{Introduction}

The literature on CEO turnover often rests on an important assumption: bad performance means a bad CEO. As a consequence, the problem a board of directors faces

\footnotetext{
${ }^{*}$ We are grateful to Chaim Fershtman and seminar participants at Erasmus University Rotterdam and the European Public Choice Society Meeting 2005 in Durham for comments.

${ }^{\dagger}$ Corresponding author: Tinbergen Institute Rotterdam, Burgemeester Oudlaan 50, 3062 PA Rotterdam, The Netherlands. Email: dominguezmartinez@few.eur.nl Tel: +31-10-4088953 Fax: $+31-10-4089147$.
} 
seems relatively simple: in case of bad performance, the CEO should be replaced. ${ }^{1}$ It is, however, a recurrent finding that substantially worse performance hardly leads to an increase in the chances of dismissal. ${ }^{2}$ To explain this tenuous relation between weak performance and turnover, boards are often characterized as "indolent" and as "ineffective rubber stampers" of top management's decisions. ${ }^{3}$ Such characterizations typically invoke descriptions of cases and interviews with top management and board members. We do not doubt the validity and accuracy of these case descriptions. Rather, we want to argue that they point to a reality in which even well-intended board members face thorny dilemmas rather than a simple problem due to the need to balance the attainment of various goals and the availability of scant information. As we will show, one important implication is that the inference from bad performance to bad CEO becomes questionable. Also, the relationship between bad performance and dismissal becomes tenuous.

Mace (1971) provides a classic account of what the relationship between a board of directors and top executives is about in reality. ${ }^{4}$ Directors lack time, knowledge and information to have an active involvement in decision-making. ${ }^{5}$ As a result, the board performs two functions. First, a board "serves as some sort of discipline" (p. 13). When making decisions, top executives take into account what they feel the board would consider acceptable actions, solutions and explanations. The second function a board performs is to decide whether to retain or replace a top executive. However, it is a very difficult task for a board to find out whether the top executive is doing a good job. The board often does not know the problems the company is facing, nor the possible actions it can take or the results it may expect, and by and large it depends on the company for information on these matters. Moreover,

\footnotetext{
${ }^{1}$ The assumption usually remains implicit by using phrases like "dismising a CEO after poor performance" and "firing an incompetent CEO" interchangeably, see e.g., Borokhovich et al. (1996, p. 340), and Weisbach (1988, p. 431). In other parts of the literature, the gist seems to be that dismissal following bad performance is an unproblematic implication, see, e.g., Warner et al. (1988) and Kaplan (1994).

${ }^{2}$ See, e.g., Brickley's (2003) discussion of the empirical research on turnover and performance.

${ }^{3}$ See Tirole (2006) for a survey of complaints.

${ }^{4}$ Mace (1971) is based on interviews with executives and directors of American companies. Lorsch and MacIver (1989), basing themselves on interviews held with directors of American companies in the second half of the 1980s, and Stiles and Taylor (2001), using interviews with directors of British companies conducted in the late 1990s, report findings that are by and large consistent with those of Mace (1971).

${ }^{5}$ Directors refers to outside directors. Mace (1971, pp. 125-127) argues that inside directors depend too much on the CEO to perform a critical role.
} 
directors seem to dislike upsetting amiable relations with the top executives. As a result, the board only decides to replace an executive if bad (financial) performance has been apparent for a considerable time (pp. 27-33).

Performance related pay is also used to direct executives' attention and effort. There is no denying that incentive pay may work well. There is, however, some evidence that observed incentive pay schemes do not provide a strong relationship between firm performance and pay ${ }^{6}$. In a recent study, Dittmann and Maug (forthcoming, p. 1) conclude that the "standard principal agent model typically used in the literature cannot rationalize observed contracts". One of the reasons may be that, in the words of Bebchuk and Fried (2003, p. 72), "managerial power and rent extraction ... have an important influence on the design of compensation packages". This would imply that incentive pay is not a remedy to an agency problem, but part of the problem itself.

In this paper we focus on the use of retention strategies as a means to discipline and screen executives in an environment in which the board has limited information about the outcomes of executives' actions. Our analysis sheds light on observed empire building; on the tenuous relationship between performance and dismissal; and casts doubt on the assumption that bad performance results from bad CEOs.

It has become one of the mainstays of the literature on corporate governance that executives will turn into empire builders if not reined in by some tight form of governance. Excessive growth or excessive investment are two forms empire building may take on. It is invariably argued that the construction of such empires reflects executives' hunger for status, power and prestige, see, e.g., Marshall (1932), Baumol (1959), Marris (1964), Williamson (1974), and Jensen (1986). Empire building, then, stems from differences in preferences between board and executives in conjunction with lack of observability, a typical moral hazard problem. Marris (1964, p. 102) adds that there is a further reason for growth: "When a man takes decisions leading to successful expansion,...he has demonstrated his powers as a manager and deserves his reward. So personal ability also becomes judged by achieved growth". Such signalling can be useful to a board possessing only limited information on an executive's ability. How, then, does a board deal with a possible conflict between

\footnotetext{
${ }^{6}$ See, e.g., Jensen and Murphy (1990) for a well known example of this. For a contrary view, see Hall and Liebman (1998).
} 
solliciting information and thwarting empire building? What is the nature of possible retention strategies? How do they differ in the way they trade-off the attainment of the goals of the board?

To answer these questions, we use a simple two-period model, in which on behalf of a board, in each period an executive designs a 'project' and decides whether or not to implement it. A project can be anything that is meant to have a substantial impact on the company, e.g., restructuring, diversification, acquisition. The quality of the project depends on the competence of the executive and on exogenous circumstances. The executive knows his competence, but the board does not. When making the implementation decision, the executive observes the exogenous circumstances, but the board does not. The board observes the implementation decision. It learns the quality of the project only when it is implemented and then only with a probability. Once the executive has made the implementation decision in the first period, the board can choose between keeping the executive and replacing him.

An important feature of our model is that a competent executive is more likely to implement a project than a less competent one. The reason is that on average a competent executive designs better projects, i.e. projects that are profitable in more adverse circumstances. Activism signals competence. The implication of this feature is that activism can be used as a screening device. As a result, the board sometimes wants a competent executive to implement projects that are not desirable per se. Moreover, the board wants incompetent executives sometimes to abstain from implementing desirable projects. The consequence is that the relationship between bad performance and low quality executive is weakened.

Having established the screening function of the implementation decision, we then show that an executive's desire to keep his job (because of prestige, power, remuneration etc.) may lead him to exploit this function, and to distort the implementation decision. The executive may partially base the implementation decision on the consequences this decision has for his career. The more the executive is moved by prestige and power, the more he is willing to distort the implementation decision - to build an empire. That is, by using the implementation decision as a screening device, the board creates a moral-hazard problem. The board may reduce this problem by dismissing an executive who has been found to have implemented too bad a project. However, the signalling function of the implementation decision 
implies that undesirable projects are implemented by competent executives in particular. As a result, a board will find it difficult to knowingly dismiss a competent executive and replace him by one of unknown quality. To overcome this problem, a board may have to stick to a norm or rule. If this is the case, dismissals stemming from bad performance will often be considered regrettable yet inevitable.

The board should also decide what to do when it does not learn the quality of an implemented project. Again, it is on the horns of a dilemma. On the one hand, it could stick to a 'no news is good news' norm, meaning that the executive is retained in the absence of definite information on the value of the implemented project. This would increase the probability that in period 2 a project will be designed by a competent executive (after all, competent executives are more likely to implement than incompetent ones). But it would also strengthen the incentive for the executive in period 1 to distort the project implementation decision. In case the board were to follow a 'no news is bad news' norm, implying the executive has to leave in the absence of information, the reverse holds. We show that a 'no news is good news' norm is preferable, ceteris paribus, if an executive does not care too much about power, if the likelihood that a replacement is highly competent is small, and if the difference in competence between executives is large.

An important insight of our analysis, then, is that boards in order to address the two main tasks they face, may have to stick to a norm to overcome a time inconsistency problem. ${ }^{7}$ In particular, under some conditions the board wants to commit itself to a retention norm that may induce it to dismiss an executive who is likely to be competent. Ex ante such a norm may be optimal as it discourages executives to distort the implementation decision too much to signal competence. Though perhaps surprising from a theoretical point of view, our result seems empirically relevant. Consider Van der Hoeven, the former CEO of Ahold. In the ten years he had been at the helm at Ahold, the company quickly expands through a corporate acquisition strategy. As a result, Ahold had been hailed as the best Dutch company for 5 consecutive years by 2002, notably for its "consistent growth and strategy". Van der Hoeven himself had been elected manager of the year in

\footnotetext{
${ }^{7}$ Lorsch and MacIver (1989) discuss how board room norms determine the effectiveness with which boards can perform their tasks.
} 
2001 and 2002, praised for his "strategic insight and entrepreneurship". 8 He had to resign in the wake of the bookkeeping fraud at Ahold's daughter US Foodservices in 2003. Further judicial inquiries later showed that Ahold's stake in companies in Sweden, Argentina, and Chile had been exaggerated with a view to inflating revenues and profits. Similarly, Bernard Ebbers, the former CEO of MCI Worldcom, received awards for his leadership from, among others, Business Week, Financial World, Wired and Time Magazine in the late 1990s and in 2000. As Van der Hoeven, he had grown the business by going on a buying spree. He was dismissed in 2002 following serious concerns about the company's finances and accounting practices. It could be argued that fraudulent practices and judicial probes led to their dismissal, not a negative decision of the board following observed bad results. However, the fraudulent practices were meant to paint too rosy a picture of the situation either company found itself in. This suggests that both executives were aware that had the real results of their corporate acquisition activities become known dismissal by the board would have been likely.

The trade-off between disciplining and screening is also felt in the relationship that exists between a parliament and a minister. The "inevitable-yet-regrettable" feeling that comes with the tension inherent in knowingly dismissing a competent agent is well expressed by the Financial Times when commenting on the dismissal of the then British Foreign Secretary Lord Carrington in 1982. The Argentinian invasion of the disputed Falkland Islands had made clear that his attempt at a diplomatic solution to the Falkland crisis had failed. The newspaper commented that "[t]he resignation of Lord Carrington is deeply regrettable - as regrettable as the events which left him with no other honourable course. He has been a notable Foreign Secretary, and has earned the highest regard internationally" , and "[i]n the public eye he was perhaps the most successful British Foreign Minister since the war." 1011

\footnotetext{
${ }^{8}$ See Management Team, issues 17 of 2001 and 2002. This Dutch magazine publishes the results of a questionnaire held among 400 Dutch managers.

${ }^{9}$ See Lexis Nexis, 'After Lord Carrington' in The Financial Times, April 6, 1982, p.14.

${ }^{10}$ See Lexis Nexis, 'The Resignation of Lord Carrington' in The Financial Times, April 6, 1982, p.15.

${ }^{11}$ The South-Korean Hwang Woo-Suk, who was "heralded as the world's leading stem-cell researcher" and was a "national hero" may well have fallen prone to the same pressure to show his ability. He falsified data used in a Science publication in 2005. He was forced to resign in December 2005 (The Economist $(2005,2006)$ )
} 


\section{Related Literature}

Our analysis contributes to the literature on boards of directors. In their survey article, Hermalin and Weisbach (2003, p. 8) observe that "the empirical literature on boards in public corporations is fairly well developed, while theory is still in its infancy". Stiles and Taylor (2001), when surveying the literature on boards, reach the same conclusion as to the dearth of theory. The paper most closely related to ours is Hermalin (2005). He models how a board selects a candidate for an executive position, forms an impression of the executive's ability, and decides whether to retain or replace him. Two important differences with our paper should be mentioned. First, Hermalin focuses on a single role of the board, screening executives' abilities. Second, the impression of the executive's ability is based on, say, presentations and interactions in board meetings, but not on observed organizational performance. As a result, the board does not have to reconcile conflicting goals. Graziano and Luporini (2003) model the same selection and retention-dismissal decision. As a board may erroneously hire an incompetent executive at the selection stage, it may be hesitant in the evaluation stage to dismiss the executive as this would signal its own lack of competence and possibly trigger its own replacement due to a takeover. We come back to some other related literature in the conclusion.

In our paper, the board uses a retention contract to deal with the moral hazard problem of the executive, analogous to the electorate using its re-election strategy to discipline politicians in political agency models. As far as we know, it is the first time that this analogy is exploited in the literature on corporate governance. As in the political agency literature, the contracts we consider are implicit, and are not enforced by some third party. They constitute expectations that are shared among the principal (board, electorate, or parliament) and the agent (executive, parliament or minister) about the situations in which an incumbent agent is retained or dismissed. ${ }^{12}$ Much of our analysis amounts to the determination of the optimal implicit contract. As noted above, such contracts could be considered norms. We argue that this (implicit contract) approach is also useful to understand certain aspects of the relationship between a board of directors and its top executives. After

\footnotetext{
${ }^{12}$ See e.g. Persson and Tabellini (2000). Barro (1973) and Ferejohn (1986) were the first to argue that the power to replace agents disciplines agents who are inclined to use office as a means of pursuing their own goals.
} 
all, just as it is hard to gauge the contribution of, say, a minister of foreign affairs to the well-being of a country it is also hard to pin down a top executive's contribution to the long-term profitability or survival of his organization. What is typically much easier to observe is whether a minister or top executive has become active: whether an agreement has been signed, a re-organization started, or a strategy implemented. Furthermore, just as a parliament does not write an explicit contract specifying when a minister will be dismissed, a typical board does not stipulate in a contract what triggers the ousting of an executive.

The remainder of this paper is organized as follows. Section 3 introduces the model. In Section 4 and 5, we establish the trade-off the board faces between disciplining and selecting executives. Section 6 discusses how the board shapes the behaviour of the executive, given that it retains the executive when it does not observe the value generated by an implemented project. Section 7 discusses how the board shapes the behaviour of the executive, given that it dismisses the executive when it does not observe the consequences of an implemented project. In Section 8 , we identify the conditions under which the board wants to retain or dismiss the executive when it does not observe the consequences of an implemented project. Section 9 concludes.

\section{The model}

We consider a two-period principal-agent model. There is a pool of agents ('executives'), a fraction $\rho$ of which is 'competent', while the other executives are 'incompetent'. At the beginning of period $t=1$, an executive is randomly drawn from this pool and becomes the incumbent. At the end of period $t=1$, the principal ('board') can dismiss the incumbent. If he is dismissed, an executive is randomly drawn from the pool of executives ${ }^{13}$ and enters office in period $t=2$. If the incumbent is not dismissed, he will also hold office in period $t=2$.

Once the incumbent has been determined for period $t \in\{1,2\}$, he designs a project, $X_{t}$. We view the value created by this project, $V_{t}$, as the addition to the organization's long term value, relative to business as usual. It depends on (i) the

\footnotetext{
${ }^{13}$ We assume that a dismissed period 1 incumbent has no chance of becoming the period 2 incumbent.
} 
incumbent's competence, and (ii) the state of the world ('market circumstances'), $\mu_{t}$. The random variable $\mu_{t}$ is uniformly distribution over $[-h, h]$. The executive knows his competence, and observes $\mu_{t}$. Once he knows the value of the project, he can either decide to implement the project ('change'), $X_{t}=1$, or to maintain the status quo ('business as usual'), $X_{t}=0$. An implemented project designed by an incompetent executive yields a value $V_{t}=V_{I C}\left(\mu_{t}\right)=p+\mu_{t}$, while an implemented project designed by a competent executive yields $V_{t}=V_{C}\left(\mu_{t}\right)=p+f+\mu_{t}$. Of course, $f>0$, implying that on average, or for given market circumstances, a competent executive designs a better project than an incompetent one. We assume $V_{C}\left(\mu_{t}=-h\right)=p+f-h<0$. As we will see, this implies that market circumstances may be so averse that even a competent executive should maintain the status quo. Similarly, we assume $V_{I C}\left(\mu_{t}=h\right)=p+h>0$, implying that market circumstances may be favourable enough such that an incompetent executive should implement the project.

Assumption $1 V_{C}\left(\mu_{t}=-h\right)<0<V_{I C}\left(\mu_{t}=h\right)$.

\section{Information}

As mentioned, we assume that the incumbent knows his competence, and that when making the decision on $X_{t}$, he also knows $\mu_{t}$. The board has limited information on which it can base its decision to retain or dismiss the incumbent. It knows the prior probability that a randomly drawn executive is competent, $\rho$, but it does not know his actual level of competence. ${ }^{14}$ It may learn about an incumbent's level of competence on the basis of the actions the incumbent takes in period one. The board observes the decision on $X_{t}$, but does not always observe whether the executive has made a good decision. Specifically, we assume that (1) if $X_{t}=0$, the board does not learn what would have been $V_{t} ;(2)$ if $X_{t}=1$, the board learns $V_{t}$ with probability $\gamma$; and (3) if $X_{t}=1$, with probability $1-\gamma$ the board remains ignorant about $V_{t}$.

\section{Preferences}

We model the board as a unitary actor. Its per period payoff is $X_{t} V_{t}$, and its goal is to maximize the total (two-period) payoff by using its retention contract. The

\footnotetext{
${ }^{14}$ What is essential in our model is that the incumbent is better informed about his level of competence and the market circumstances than the board.
} 
possible retention strategies are discussed in the following sections. The executive in our model represents a top executive of an organization. He derives utility from holding office - power, prestige, visibility, remuneration etc.- to which we refer as benefits from holding office, $\lambda$. Besides caring about these benefits, the executive also cares to some degree about the value of the implemented project. We assume that an executive's per period payoff equals

$$
\begin{cases}X_{t} V_{t}+\lambda & \text { if in office in period } t \\ X_{t} V_{t} & \text { otherwise }\end{cases}
$$

The goal of the incumbent in period $t=1$ is to maximize his total (two-period) payoff using his implementation decision and given the retention strategy of the board; the goal of the incumbent in period $t=2$ is to maximize period 2 payoff. To minimize notation, preferences are represented by (1). Implicit in (1) is that an executive who is dismissed in period 1 and an executive who is not dismissed in period 1 care to the same extent about the value created in period 2 . This is often unrealistic. However, important for our results is that the period 1 incumbent cares to some extent about the value created in period 2, even if he has been dismissed. This may result from identification with the organization one has been leading. Of course, the degree of identification with an organization varies from person to person and from organization to organization.

Following the principal-agent literature, we assume that first the principal sets the terms of the contract and next the agent determines his optimal behaviour given those terms. In our case, the board determines under what conditions an executive is retained or dismissed (the implicit contract), and then the executive decides what projects to implement.

\section{Timing}

Period 1

- Nature determines the type of incumbent, draws $\mu_{1}$, and reveals type and $\mu_{1}$ to the incumbent, but not to the board.

- The incumbent takes a decision on the project, $X_{1} \in\{0,1\}$. 
- The board observes the decision on $X_{1}$. If $X_{1}=1$, then with probability $\gamma$ the board observes $V_{1}$.

- The board chooses either to keep the incumbent or to replace him.

\section{Period 2}

- If the incumbent was replaced in period 1 , nature draws a type and reveals it to the new incumbent, but not to the board.

- Nature draws $\mu_{2}$ and reveals it to the incumbent, but not to the board.

- The incumbent takes a decision on the project, $X_{2} \in\{0,1\}$.

\section{The Need for Selection}

Suppose that the board does not select an executive on the basis of first-period outcomes. Thus, no matter what, the board keeps the first-period incumbent. ${ }^{15}$ In that case, strategic considerations stemming from the desire to hold office play no role. A project is implemented in period $t$ if and only if its value is positive. Given the executive's ability, the per period payoff is maximized. Suppose the incumbent is competent. Then, $X_{t}=1$ is chosen if and only if $V_{C}\left(\mu_{t}\right) \geq 0$. Given the executive's ability, the per period payoff is maximal. Suppose the executive is competent. He chooses to implement the project if and only if $V_{C}\left(\mu_{t}\right) \geq 0$, or if $\mu_{t} \geq-p-f$. This implementation decision yields a per period payoff to the board equal to

$$
\Pi_{C}=\operatorname{Pr}\left(V_{C}\left(\mu_{t}\right) \geq 0\right) E\left(V_{C}\left(\mu_{t}\right) \mid V_{C}\left(\mu_{t}\right) \geq 0\right)=\frac{1}{4 h}(p+h+f)^{2}
$$

Similarly, an incompetent executive implements a project if $\mu_{t} \geq-p$, yielding a per period profit equal to $\Pi_{I C}=\frac{1}{4 h}(p+h)^{2}$. Clearly, this implies that a board prefers a competent executive to an incompetent one. We have now arrived at the drawback of always keeping the executive. Since a competent executive implements a project in market circumstances in which an incompetent would refrain from doing so, project implementation (activism) is a signal of competence. Maintaining the

\footnotetext{
${ }^{15}$ Alternatively, the principal could always dismiss the agent.
} 
status quo (passivity) is a signal of incompetence. The board could increase its expected second period payoff by dismissing an executive who has maintained the status quo.

Define $\Pi_{\rho}:=\rho \Pi_{C}+(1-\rho) \Pi_{I C}$. This is the expected project payoff if an executive of unknown or 'average' quality were to hold office. We will assume that an incompetent executive who holds office cares so much about being retained that he does not ask to be replaced by an executive of unknown quality. This means that $\left[\lambda+\Pi_{I C}\right]>\left[\Pi_{\rho}\right]$, where here and throughout the paper second-period payoffs are given in square brackets. If this inequality were not to hold, the board could simply have asked the incumbent as to his competence level and would have obtained an honest answer.

Assumption 2 The benefits of holding office are sufficiently high, $\lambda>\Pi_{\rho}-\Pi_{I C}$, such that the board does not believe the executive's claim as to his competence.

\section{Selection induces moral hazard}

The previous section shows that when the board always keeps the executive, a competent executive is more likely to implement a project than an incompetent one $\left(\mu_{C}<\mu_{I C}\right)$. As a result, executive activism signals competence. In this section we assume that the board selects the second-period incumbent on the basis of the firstperiod outcome. In line with the signalling function of the implementation decision, activism is rewarded by retention, whereas an inactive executive is sent home. We show that this influences the behaviour of the incumbent in period 1. Activism gives way to 'empire building'.

Consider a competent executive who has observed $\mu_{1}$ in period $t=1 .{ }^{16}$ He will implement the project (rather than reject it) if and only if $V_{C}\left(\mu_{1}\right)+\lambda+\left[\Pi_{C}+\lambda\right] \geq$ $\lambda+\left[\Pi_{\rho}\right]$. This inequality determines a cut-off value $V_{C}^{*}(\lambda)$ such that the project is implemented if and only if

$$
V_{C}\left(\mu_{1}\right) \geq V_{C}^{*}(\lambda):=-\left(\Pi_{C}-\Pi_{\rho}\right)-\lambda
$$

\footnotetext{
${ }^{16}$ Of course, as the game ends after period 2, the second-period incumbent chooses $X_{2}=1$ if and only if the expected project payoff is positive.
} 
Note that because $\Pi_{\rho}<\Pi_{C}$, we have $V_{C}^{*}(\lambda)<0$. Equation (2) says therefore that in period 1 a competent executive is willing to make a loss on a project in order to gain more in the second period. These gains are twofold: benefits from office, $\lambda$, and a foregone drop in project payoff $\Pi_{C}-\Pi_{\rho}$.

Similarly, an incompetent executive implements the project if $V_{I C}\left(\mu_{1}\right)+\lambda+$ $\left[\Pi_{I C}+\lambda\right] \geq \lambda+\left[\Pi_{\rho}\right]$. This determines a cut-off value $V_{I C}^{*}(\lambda)$ such that the project is implemented if and only if

$$
V_{I C}\left(\mu_{1}\right) \geq V_{I C}^{*}(\lambda):=\left(\Pi_{\rho}-\Pi_{I C}\right)-\lambda
$$

Because of Assumption 2, $V_{I C}^{*}(\lambda)<0$. A comparison of (2) and (3) shows that a competent executive implements projects for lower values of $V_{1}$. Furthermore, for a given value of $\mu_{1}, V_{C}\left(\mu_{1}\right)>V_{I C}\left(\mu_{1}\right)$. Implementation is therefore more likely with a competent than with an incompetent executive.

To highlight the signalling function of the implementation decisions suppose that even if $\lambda=0$ an incumbent is able to signal his competence only through his implementation decision. Equations (2) and (3) imply that the board would have wanted both a competent and an incompetent executive to deviate from the implementation decision that maximizes per period payoff. This can be seen from the first part on the right hand side of $(2)$ and $(3): V_{C}^{*}(0)=-\left(\Pi_{C}-\Pi_{\rho}\right)<0$ and $V_{I C}^{*}(0)=\left(\Pi_{\rho}-\Pi_{I C}\right)>0$. A competent executive may decide to implement a bad project, while an incompetent executive may decide not to implement a good project. Such deviations from the first-best implementation decision are the price the board is willing to pay for gaining information about the executive's competence. These deviations should therefore not be considered distortions. They perform a signalling function. The only parts of (2) and (3) that are distortions from the board's point of view stem from the executive's benefits from holding office concerns, $\lambda$.

Figure 1 illustrates our analysis so far. Panels A and B show the range of values of $V_{1}$ for which the project is implemented or the status quo is maintained by a competent executive in case $\lambda=0$ and $\lambda>0$, respectively. Panels $\mathrm{C}$ and $\mathrm{D}$ show the same for an incompetent executive. The desire to hold office widens the range of parameters for which $X_{1}=1$. The board does not want (i) a competent executive to choose $X_{1}=1$ if $V_{1} \in\left[V_{C}^{*}(\lambda), V_{C}^{*}(0)\right)$; nor (ii) an incompetent executive to choose 


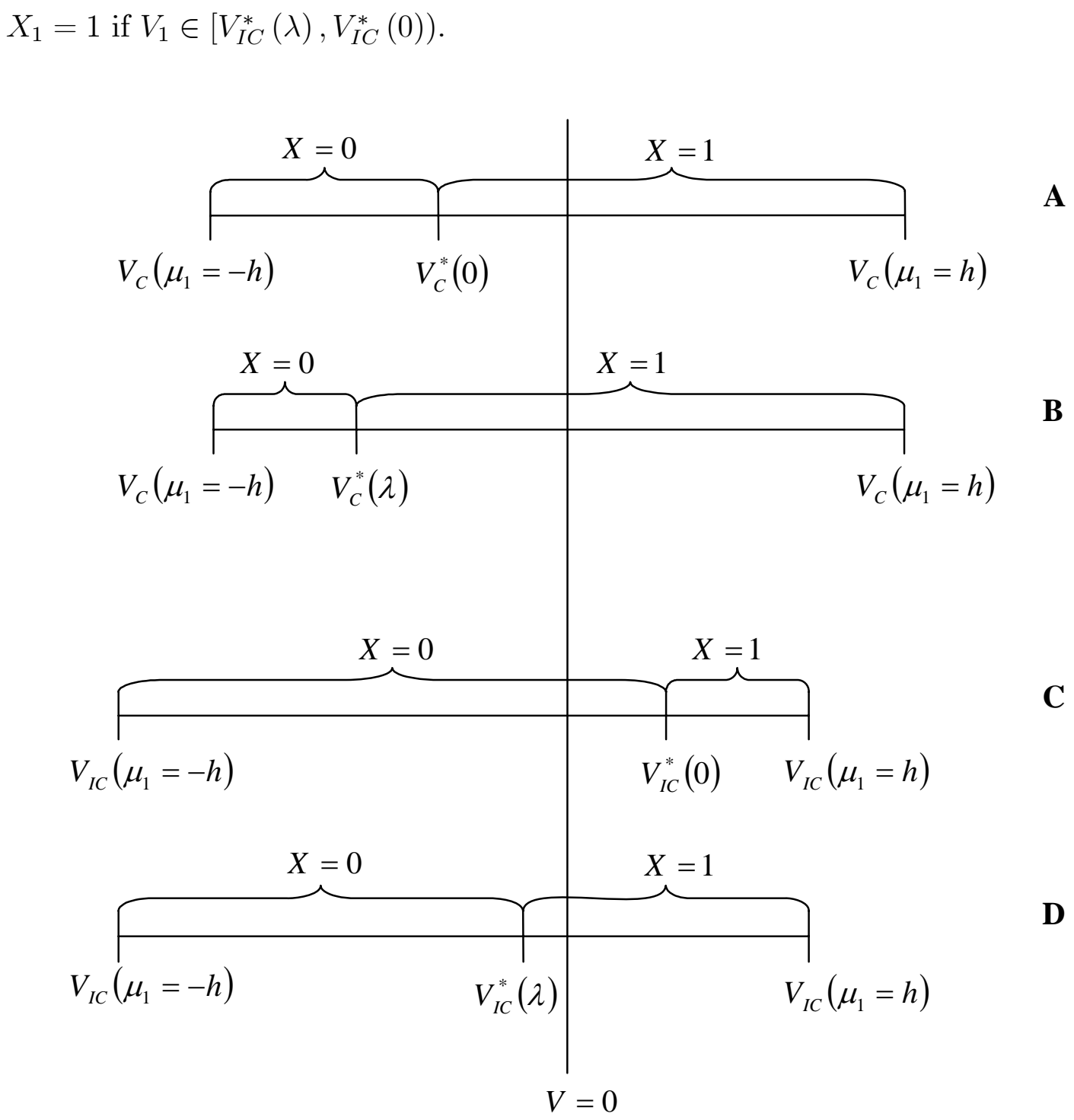

Figure 1

In comparison with always keeping the executive, the benefit of keeping the executive only if he has implemented a project is an increase in expected payoff in the second period. This stems from the signalling function of the first-period implementation decision. In practice, the quality of executives improves. The downside of keeping the executive only if he has implemented a project, however, is that he distorts the implementation decision. Selecting on the basis of outcomes leads to a moral hazard problem. In practice, executives become empire builders (see, e.g., Baumol (1959), Williamson (1974), and Jensen (1986)).

It is also clear from Figure 1, parts B and D, that the implementation of value- 
destroying projects may result from both competent and incompetent executives. The tie between bad performance and incompetent management is broken because the board faces two tasks, both disciplining and screening.

So far we have focused on two extreme possible strategies for the board. However, as the board occasionally observes the project value, $V_{1}$, it may condition its decision to keep the executive not merely on a project being implemented, but also on information on the project value. By keeping the executive only if the value of the project exceeds a threshold value, $V_{1}>a$, the board may discipline ${ }^{17}$ the executive, that is, reduce the executive's incentive to distort the implementation decision. What remains to be decided is what to do in case the project is implemented, but the project's value remains unknown. In the next section, we assume the retention contract 'no news is good news': the board keeps the executive if it observes implementation but does not observe the project value. In Section 7 , we assume 'no news is bad news'. The executive is replaced if the board does not observe the project value. A remark on terminology is in order. We use threshold value when discussing the board's retention contract, and cutoff value when discussing the executive's implementation strategy.

\section{Retention Contract 1: 'No news is good news'}

Under retention contract 1 the board

- dismisses the executive in case no project has been implemented,

- dismisses the executive in case a project has been implemented, and observes $V_{1} \leq a$

- keeps the executive in case a project has been implemented, and does not observe $V_{1}$

- keeps the executive in case a project has been implemented, and observes $V_{1}>a$.

\footnotetext{
${ }^{17}$ This is the expression used by Mace (1971), see the introduction.
} 
Our main concern is the determination of the threshold value $a$ that is optimal from the board's point of view. The choice of $a$ determines the degree to which an executive is disciplined and also the likelihood that a competent executive is selected for the second period.

To see how the board's choice of a may affect the executive's implementation decision in period 1, consider panels B and D in Figure 1. Suppose that the board chooses $a \in\left[V_{C}^{*}(\lambda), V_{I C}^{*}(\lambda)\right)$. Then, in case the incumbent is competent, his decision on $X_{1}$ may be affected by $a$. If the board observes $V_{1} \leq a, X_{1}=1$ leads to dismissal. Hence, compared to the situation of the previous section, in which $X_{1}=1$ always leads to keeping the executive, the incentive to choose $X_{1}=1$ is weakened. If the executive in office in period 1 is incompetent, $a \in\left[V_{C}^{*}(\lambda), V_{I C}^{*}(\lambda)\right)$ does not affect his implementation decision, as $a$ is non-binding. Now suppose that the board chooses $a \geq V_{I C}^{*}(\lambda)$. Then, $a$ is binding for both a competent and an incompetent executive. Relative to (2) and (3), the incentive to choose $X_{1}=1$ is weakened.

The upshot is that the board's choice of $a$ amounts to choosing between two alternatives. First, by choosing $a \in\left[V_{C}^{*}(\lambda), V_{I C}^{*}(\lambda)\right)$, the board chooses to discipline competent executives, taking for granted that if an incompetent executive is in office, the implementation decision will be distorted, see (3). Second, by choosing $a \geq$ $V_{I C}^{*}(\lambda)$, the board affects the implementation decision of either type of executive. We now first derive how the choice of $a$ influences the behaviour of either type of executive in isolation.

\subsection{Case 1: disciplining a competent executive}

Ideally, the board wants a competent incumbent to choose $X_{1}=1$ if and only if $V_{1}>V_{C}^{*}(0)$. However, a competent executive chooses $X_{1}=1$ if $V_{1} \geq V_{C}^{*}(\lambda)$, see (2). By using a threshold value $a$ in his retention contract, the board can discipline the executive. We say that an executive is 'fully disciplined' if he no longer distorts the implementation decision at all, while an executive is said to be 'partially disciplined' if the distortion is merely reduced. Let $\widehat{V}_{C}$ denote the cut-off value used by a competent incumbent if the board sets a sufficiently large. Notice that to have an effect on a competent executive's implementation decision, the board should set $a \geq \widehat{V}_{C}$. Thus, assume $a \geq \widehat{V}_{C}$. Now suppose that a competent 
executive observes $V_{C}\left(\mu_{1}\right)<a$. He will implement the project if $V_{C}\left(\mu_{1}\right)+\lambda+$ $\left[(1-\gamma)\left(\Pi_{C}+\lambda\right)+\gamma\left(\Pi_{\rho}\right)\right] \geq \lambda+\left[\Pi_{\rho}\right]$. Hence, the executive implements the project if

$$
V_{C}\left(\mu_{1}\right) \geq \widehat{V}_{C}(\lambda):=-(1-\gamma)\left(\Pi_{C}-\Pi_{\rho}\right)-(1-\gamma) \lambda
$$

Four remarks are in order. First, for $V_{1} \in\left[\widehat{V}_{C}(\lambda), a\right]$ the executive chooses implementation in the hope that the board does not observe the project outcome, so that he keeps office. Second, the board can change the value of $a$ without affecting the cutoff value used by the executive as long as it sets the threshold value $a$ such that $a \geq \widehat{V}_{C}(\lambda)$. Third, a comparison between (2) and (4) shows that $V_{C}^{*}(\lambda)<\widehat{V}_{C}(\lambda)$. Hence, the executive is at least partially disciplined. Fourth, for $\lambda<\lambda^{*}:=\frac{\gamma}{1-\gamma}\left(\Pi_{C}-\Pi_{\rho}\right)$, the cutoff value would satisfy $V_{C}^{*}(0)<\widehat{V}_{C}(\lambda)$. This means that if the competent executive cares little about holding office, the effect of setting a threshold may be too strong: the beneficial screening function of the implementation decision is hampered. But this also implies that for $\lambda<\lambda^{*}$, the board can induce the executive to use $V_{C}^{*}(0)$ as his threshold value by setting $a=V_{C}^{*}(0)$. This effectively stops the executive from distorting the implementation decision.

Lemma 1 Suppose the retention contract 'no news is good news'. If $\lambda<\lambda^{*}$ holds, then $a=V_{C}^{*}(0)$ is the unique threshold value that guarantees that a competent executive is fully disciplined. If instead $\lambda \geq \lambda^{*}$ holds, then the board can only partially discipline a competent executive, by setting $a \geq \widehat{V}_{C}(\lambda)$. The cut-off value used by the disciplined executive is

$$
\widehat{V}_{C}= \begin{cases}V_{C}^{*}(0) & \text { if } \lambda<\lambda^{*} \\ \widehat{V}_{C}(\lambda)=-(1-\gamma)\left(\Pi_{C}-\Pi_{\rho}\right)-(1-\gamma) \lambda & \text { if } \lambda \geq \lambda^{*}\end{cases}
$$

with $\widehat{V}_{C} \in\left(V_{C}^{*}(\lambda), V_{C}^{*}(0)\right] \cdot{ }^{18}$

\footnotetext{
${ }^{18}$ If $\lambda<\lambda^{*}$, the disciplined executive implements the project if and only if $V_{1}>V_{C}^{*}(0)$. Hence, to be precise, the cut-off value should be $\lim _{\varepsilon \downarrow 0} V_{C}^{*}(\varepsilon)$.
} 


\subsection{Case 2: disciplining an incompetent executive}

We now turn to the possibility that the board sets the threshold value $a$ such that the behaviour of an incompetent executive is affected, $a \geq V_{I C}^{*}(\lambda)$.

Lemma 2 Suppose the retention contract 'no news is good news'. It is not possible to fully discipline an incompetent executive. An incompetent executive can be partially disciplined by setting $a \geq \widehat{V}_{I C}(\lambda)=(1-\gamma)\left(\Pi_{\rho}-\Pi_{I C}\right)-(1-\gamma) \lambda$. Then, the board induces an incompetent executive to choose $X_{1}=1$ if and only if $V_{1} \geq \widehat{V}_{I C}(\lambda)$, where $\widehat{V}_{I C}(\lambda) \in\left(V_{I C}^{*}(\lambda), V_{I C}^{*}(0)\right)$.

Proof. Suppose $a$ is such that the incompetent executive's implementation strategy is affected (ie., $\left.a>V_{I C}^{*}(\lambda)\right)$. Clearly, for $V_{I C}\left(\mu_{1}\right) \geq a$, the project will be implemented. For $V_{I C}\left(\mu_{1}\right)<a$, implementation yields $V_{I C}\left(\mu_{1}\right)+\lambda+$ $\left[\gamma \Pi_{\rho}+(1-\gamma)\left(\Pi_{I C}+\lambda\right)\right]$, while maintaining the status quo yields $\lambda+\left[\Pi_{\rho}\right]$. It is now straightforward to check that $X_{1}=1$ is preferred to $X_{1}=0$ if $V_{I C}\left(\mu_{1}\right) \geq$ $\widehat{V}_{I C}(\lambda)=(1-\gamma)\left(\Pi_{\rho}-\Pi_{I C}\right)-(1-\gamma) \lambda$, where $V_{I C}^{*}(\lambda)<\widehat{V}_{I C}(\lambda)<V_{I C}^{*}(0)$. As a result, disciplining is partial, not full.

Lemma 2 states that the board can only partially discipline an incompetent executive. To understand why the board cannot fully discipline an incompetent executive, suppose that the threshold value set by the board equals $a=V_{I C}^{*}(0)$ and that the executive observes $\mu_{1}$ such that $V_{I C}\left(\mu_{1}\right)=V_{I C}^{*}(0)$, and $\lambda>0$. Recall that $V_{I C}^{*}(0)$ is the cut-off value the executive uses if he does not care about the benefits from office, and if implementation is sufficient for re-appointment. In the current situation, the executive does care about holding office, and implementation is merely necessary for re-appointment. As a result of $\lambda>0$, the executive now strictly prefers implementation to maintaining the status quo from a benefits point of view. Now take the project value point of view. If implementation is sufficient to be retained, an incompetent incumbent has to maintain the status quo to ensure that he is replaced by someone of 'average' quality such that expected payoff goes up in the second period. However, with retention contract 1, implementation no longer guarantees retention. Therefore, the benefits of dismissal (a higher expected period two payoff) can now be combined with implementation of a profitable project in period 1 (recall that $V_{I C}^{*}(0)>0$ ). As a result, the executive now strictly prefers implementation to maintaining the status quo. As the executive prefers $X=1$ to 
$X=0$ both from a project and a career point of view when $V_{I C}\left(\mu_{1}\right)=V_{I C}^{*}(0)$, he cannot be fully disciplined.

\subsection{Choice of threshold value $a$}

Above we have analysed the effect of a threshold value $a$ on the behaviour of each type of incumbent in isolation. We now analyse how the choice of $a$ influences the board's utility. To do so, we look both at the effect of the choice of $a$ on the discipline exerted in the first period and on the likelihood that a competent executive is selected for the second period.

Proposition 1 Suppose the retention contract 'no news is good news'. The board has two options. It either disciplines a competent executive as much as possible (be it fully or partially) by setting $a=\widehat{V}_{C}$. Or it disciplines both types of executive by setting $a \in\left[\widehat{V}_{I C}(\lambda), V_{I C}\left(\mu_{1}=h\right)\right]$.

The Proposition follows, to a large extent, from Lemma 1 and Lemma 2. Therefore, we only provide an informal proof of the Proposition. To grasp the basic ideas behind Proposition 1 consider Figure 2.

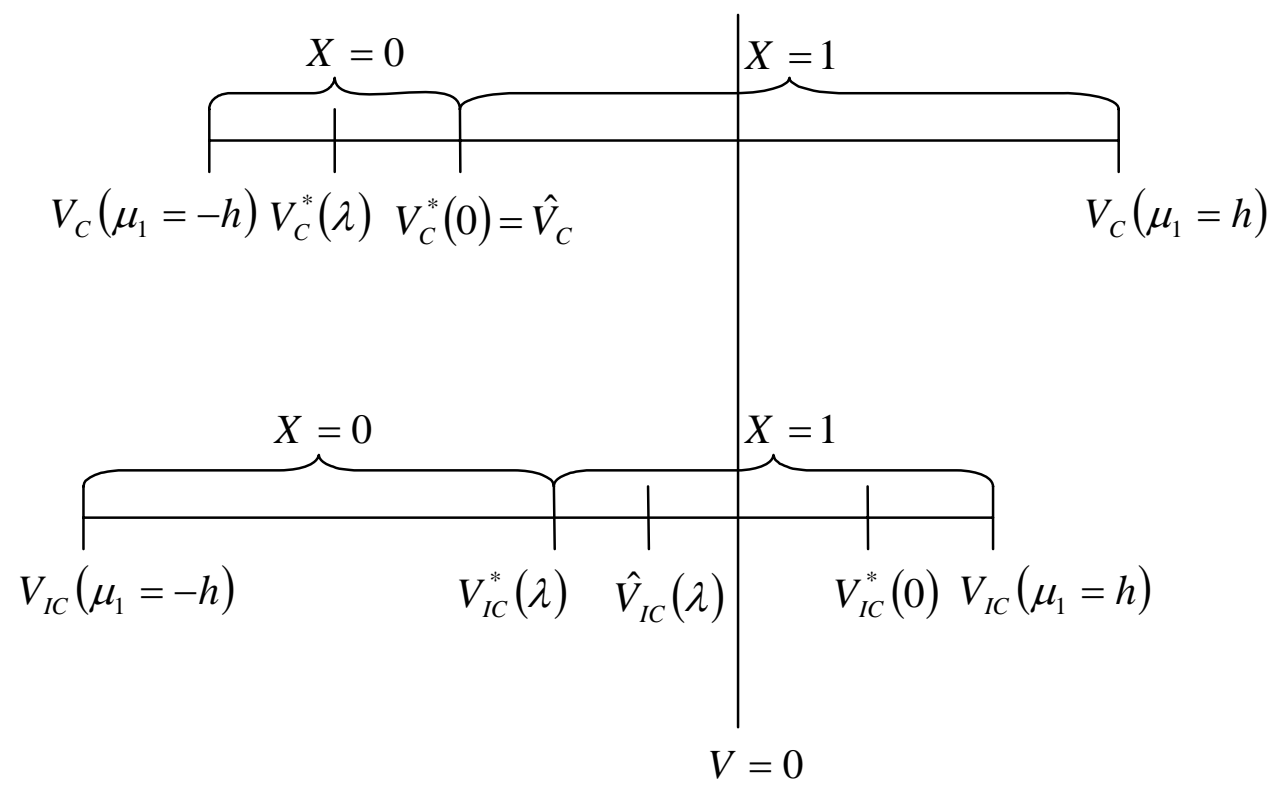

Figure 2 
Figure 2 describes a situation where $\widehat{V}_{C}<V_{I C}^{*}(\lambda) .{ }^{19}$ Suppose that the board sets $a<V_{I C}^{*}(\lambda)$. The implication is that the board sets $a$ so as to influence the behaviour of a competent executive, taking for granted that an incompetent executive's implementation decision is based on $V_{I C}^{*}(\lambda)$. In Section 5 we have argued that, given that the board does not know the executive's ability, ideally it wants a competent executive to choose implementation only if $V_{1}>V_{C}^{*}(0)$. Lemma 1 states that if $\lambda<\lambda^{*}$, the board can reach this goal by setting $a=V_{C}^{*}(0)$ : a competent incumbent can be fully disciplined. If instead $\lambda \geq \lambda^{*}$, the board can only partially discipline a competent executive, $\widehat{V}_{C}(\lambda)<V_{C}^{*}(0)$, by setting $a \geq \widehat{V}_{C}(\lambda)$. Has the board an incentive to set $a>\widehat{V}_{C}(\lambda)$, rather than $a=\widehat{V}_{C}(\lambda)$ ? The answer is in the negative. When the board observes that $V_{1} \in\left[\widehat{V}_{C}(\lambda), V_{I C}^{*}(\lambda)\right)$, it knows the incumbent is competent. The incumbent executive should be kept.

Now suppose that the board sets $a \geq \widehat{V}_{I C}(\lambda)$. Then, the board disciplines an incompetent executive, and since $\widehat{V}_{C}<\widehat{V}_{I C}(\lambda)$, it also disciplines a competent executive. Thus, by choosing $a \geq \widehat{V}_{I C}(\lambda)$, the board maximally uses the disciplining possibilities within the 'no news is good news' contract. Notice that if the board observes a value $V_{1} \in\left[\widehat{V}_{C}, \widehat{V}_{I C}(\lambda)\right)$, it is aware that the executive is competent, but nevertheless dismisses him. The price of a contract that disciplines an incompetent executive is that the possibilities for selecting a competent executive are not fully exploited. At which value should the board set $a$ ? Recall from Section 5 that ideally the board wants an incompetent executive to choose implementation if $V_{I C}\left(\mu_{1}\right) \geq$ $V_{I C}^{*}(0)$. However, as Lemma 2 states, within the 'no news is good news' contract the board cannot fully discipline an incompetent executive. The best it can do is to partially discipline an incompetent executive by setting $a \geq \widehat{V}_{I C}(\lambda)$. Does the board have an incentive to set $a>\widehat{V}_{I C}(\lambda)$, rather than $a=\widehat{V}_{I C}(\lambda)$ ? For $a \in\left[\widehat{V}_{I C}(\lambda), V_{I C}\left(\mu_{1}=h\right)\right]$, the value of $a$ has no effect on the implementation decision of either type of executive, nor on selection. The board should not set $a>$ $V_{I C}\left(\mu_{1}=h\right)$, as $V_{1}>V_{I C}\left(\mu_{1}=h\right)$ is clear evidence that the executive is competent.

The upshot is as follows. Recall that equating project implementation and retention induces the executive to become overly active. The board can use information

\footnotetext{
${ }^{19}$ If $V_{I C}^{*}(\lambda) \leq \widehat{V}_{C}$, then the board's dominant strategy is to discipline also the incompetent executive. In this case setting $a=\widehat{V}_{C}$ also affects the behavior of an incompetent executive. Hence, disciplining only a competent executive is not an option.
} 
on the value of implemented projects that occassionally becomes available to condition its retention decision. The contract 'no news is good news' offers two options for a board to guide the behaviour of an executive. First, the board can focus on disciplining a competent executive only $\left(a=\widehat{V}_{C}\right)$. We refer to this option as the selection option, as this option maximally exploits the selection possibilities. Second, the board can focus on disciplining an incompetent executive and thereby also on disciplining a competent executive $\left(a=\widehat{V}_{I C}(\lambda)\right)$. We refer to this option as the disciplining option. The benefit of the selection option is a higher probability that in period two the incumbent will be competent. This probability is directly related to the length of the interval $\left[\widehat{V}_{C}, V_{I C}^{*}(\lambda)\right]$, see Figure 2. The benefit of the disciplining option is that an incompetent executive distorts the implementation decision less. This benefit depends positively on the length of the interval $\left[V_{I C}^{*}(\lambda), \widehat{V}_{I C}(\lambda)\right]$.

One important question remains: Which option does the board choose? Proposition 2 describes how the answer to this question depends on the parameters of the model.

Proposition 2 Suppose $\widehat{V}_{C}<V_{I C}^{*}(\lambda)$. Then, an increase in $\lambda$ or $\gamma$, or a decrease in $\Pi_{C}-\Pi_{I C}$ or $\rho$, widens the range of parameters for which the board chooses the disciplining option, rather than the selection option. If instead $V_{I C}^{*}(\lambda) \leq \widehat{V}_{C}$, the board's dominant strategy is to choose the disciplining option by setting $a=\widehat{V}_{I C}(\lambda)$.

\section{Proof: Appendix}

Clearly, if $V_{I C}^{*}(\lambda) \leq \widehat{V}_{C}$, then the board chooses the disciplining option. The reason is that in that case, if the board were to choose $a=\widehat{V}_{C}$, it would also affect an incompetent executive's behaviour. Therefore, disciplining a competent executive only, the selection option, is not a real option. Another way of looking at this result is that, as discussed earlier, the benefit of the selection option is directly related to the length of the interval $\left[a, V_{I C}^{*}(\lambda)\right]$. Obviously, if $V_{I C}^{*}(\lambda) \leq a$, then there is no benefit of the selection option.

Now suppose that $\widehat{V}_{C}<V_{I C}^{*}(\lambda)$, so that the board really can choose between the selection and disciplining option. To determine how a change in the parameters affects the board's choice as to the two options, we compare the effects of such a change on the lengths of the intervals $\left[\widehat{V}_{C}, V_{I C}^{*}(\lambda)\right]$ and $\left[V_{I C}^{*}(\lambda), \widehat{V}_{I C}(\lambda)\right]$. We focus 
on the situation where $\lambda \geq \lambda^{*}$ (and so $\widehat{V}_{C}=\widehat{V}_{C}(\lambda)^{20}$ ). It is easy to show that

$$
\begin{aligned}
V_{I C}^{*}(\lambda)-\widehat{V}_{C} & =\Pi_{C}-\Pi_{I C}-\gamma\left(\Pi_{C}-\Pi_{\rho}\right)-\gamma \lambda \\
& =(1-\gamma(1-\rho))\left(\Pi_{C}-\Pi_{I C}\right)-\gamma \lambda
\end{aligned}
$$

and

$$
\begin{aligned}
\widehat{V}_{I C}(\lambda)-V_{I C}^{*}(\lambda) & =-\gamma\left(\Pi_{\rho}-\Pi_{I C}\right)+\gamma \lambda \\
& =-\gamma \rho\left(\Pi_{C}-\Pi_{I C}\right)+\gamma \lambda
\end{aligned}
$$

The larger is the value of (6), the more attractive is the selection option. In contrast, the larger is the value of (7), the more attractive is the disciplining option. ${ }^{21}$

An increase in benefits from holding office $\lambda$ decreases the value the board attaches to the selection option, see (6), and increases the value of the disciplining option, see (7). The reason for this result is clear. As explained in Section 5, the executive's desire to hold office is the reason the board wants to discipline in the first place.

In our model, the board wants a competent, rather than an incompetent, executive to design a project. It is therefore hardly surprising that an increase in $\Pi_{C}-\Pi_{I C}$ widens the range of parameters for which the board chooses the selection option. It is worth noting that an increase in $\Pi_{C}-\Pi_{I C}$ decreases $(7)$. The reason is that an increase in $\Pi_{C}-\Pi_{I C}$ raises the cost of distorting the implementation decision for the executive. As a result, the need for disciplining the executive diminishes.

An increase in $\gamma$ implies that the probability that the board learns the project outcome increases. Important for the effect of $\gamma$ on the choice between the selection and disciplining option is that the possibility of observing $V$ is a prerequisite for disciplining executives. It is therefore quite intuitive that a rise in $\gamma$ increases the attractiveness of the disciplining option. This is borne out by the fact that the value of the discipling option, (7), increases in $\gamma$. By the same token, the value of the selection option, (6), goes down as a higher likelihood of the project value being observed reduces a competent executive's eagerness to implement.

\footnotetext{
${ }^{20}$ The analysis of the case $\lambda<\lambda^{*}$ with $\widehat{V}_{C}=V_{C}^{*}(0)$ is analogous.

${ }^{21}$ Recall from Assumption 2 that $\lambda>\Pi_{\rho}-\Pi_{I C}$, and so the expression in (7) is strictly positive.
} 
The parameter $\rho$ denotes the probability that an executive is competent. The direct effect of an increase in $\rho$ is a smaller loss stemming from not disciplining incompetent executives. This is why an increase in $\rho$ widens the range of parameters for which the board chooses the selection option $((6)$ goes up in $\rho$, while (7) goes down).

\section{Retention contract 2: 'No news is bad news'}

Under retention contract 2 the board

- dismisses the executive in case no project has been implemented,

- dismisses the executive in case a project has been implemented, and observes $V_{1}<a$,

- dismisses the executive in case a project has been implemented, and does not observe $V_{1}$

- keeps the executive in case a project has been implemented, and observes $V_{1} \geq a$.

Notice that the main difference between contracts 1 and 2 resides in the board's decision in case it does not observe the value of an implemented project. With contract 1 , the executive is kept in office. This makes sense from a selection perspective. After all, a competent executive is more likely to implement a project than an incompetent one. It has the disadvantage of inducing the incumbent to distort the implementation decision as he hopes a project of low value will go unnoticed. Retention contract 2 dashes any such hopes. By dismissing the incumbent in case activism does not lead to any visible results, it becomes easy to discipline the incumbent. However, it still is the case that a competent executive is more likely to implement a project than an incompetent one. The consequence is that in the absence of visible results, the board is more likely to send home a competent than an incompetent executive.

Consider the executive's behaviour if the board retains him if and only if he implements a project and the project's payoff becomes visible. Suppose the incumbent is competent. He implements a project of value $V_{C}\left(\mu_{1}\right)$ if and only if 


$$
\begin{aligned}
& V_{C}\left(\mu_{1}\right)+\lambda+\left[\gamma\left(\Pi_{C}+\lambda\right)+(1-\gamma) \Pi_{\rho}\right]>\lambda+\left[\Pi_{\rho}\right] \text { or if } \\
& V_{C}\left(\mu_{1}\right) \geq \widetilde{V}_{C}(\lambda):=-\gamma\left(\Pi_{C}-\Pi_{\rho}\right)-\gamma \lambda
\end{aligned}
$$

An incompetent incumbent implements a project if and only if

$$
V_{I C}\left(\mu_{1}\right) \geq \widetilde{V}_{I C}(\lambda):=\gamma\left(\Pi_{\rho}-\Pi_{I C}\right)-\gamma \lambda
$$

Note that $\widetilde{V}_{C}(\lambda)<\widetilde{V}_{I C}(\lambda)$. As in the previous section, a competent incumbent opts for $X_{1}=1$ for more values of $V_{1}$ and therefore of $\mu_{1}$ than an incompetent incumbent. It is useful to compare (8) and (9) with (2) and (3), respectively. Recall that the latter equations describe the cut-off values in case project implementation (activism) is sufficient for re-appointment. With $\lambda=0,(8)$ and (9) denote the optimal implementation decisions from the board's point of view, given that the executive is dismissed if outcomes are not observed. Clearly, as a competent incumbent is sent home with probability $1-\gamma$ if he implements a project, the board is now less willing to accept a first-period loss. Analogously, the board is now less willing to forego a profitable project in period one to find out that the incumbent is incompetent: with probability $1-\gamma$ the incumbent would have been replaced anyway. This comparison shows that 'no news is bad news' allows for a lower degree of screening than 'no news is good news'. The advantage of the retention contract 'no news is bad news' is that it gives weaker incentives to executives to distort the implementation decision $(\gamma \lambda$ in (8) and (9) instead of $\lambda$ in (2) and (3)).

If the board uses the 'no news is bad news' retention contract, it can fully discipline a competent executive, independent of the degree to which an executive derives benefits from holding office.

Lemma 3 Suppose 'no news is bad news'. The board can fully discipline a competent executive by setting $a=\widetilde{V}_{C}(0)$. A competent executive then uses the cut-off value $\widetilde{V}_{C}(0)$.

Proof: Consider a project with $V_{C}\left(\mu_{1}\right)<\widetilde{V}_{C}(0)$. Implementation leads to a project loss (as $\widetilde{V}_{C}(0)<0$, see Eq $(8)$ ), and dismissal in period 1. Maintaining the status quo is better as the project loss is foregone. Now suppose $V_{C}\left(\mu_{1}\right) \geq \widetilde{V}_{C}(0)$. Implementation yields $V_{C}\left(\mu_{1}\right)+\lambda+\left[\gamma\left(\Pi_{C}+\lambda\right)+(1-\gamma) \Pi_{\rho}\right]$ whereas maintaining 
the status quo yields $\lambda+\left[\Pi_{\rho}\right]$. Implementation is best as $V_{C}\left(\mu_{1}\right) \geq-\gamma\left(\Pi_{C}-\Pi_{\rho}\right)-$ $\gamma \lambda=\widetilde{V}_{C}(0)-\gamma \lambda$ holds. QED

Now consider the case that the board wants to discipline an incompetent executive, $a \in\left(\widetilde{V}_{I C}(\lambda), V_{I C}\left(\mu_{1}=h\right)\right]$. It can at most partially discipline an incompetent executive. As with retention contract 1 , if it decides to discipline an incompetent executive, it also disciplines a competent executive.

Lemma 4 Suppose 'no news is bad news'. If the board decides to discipline an incompetent executive, its (weakly) dominant strategy is to set $a=0$, thereby inducing both types of executive to implement only profitable projects in period 1.

The intuition for this result is as follows. By setting $a \in\left[\widetilde{V}_{I C}(\lambda), 0\right)$, the board induces either type of executive to implement a project only if $V_{1} \geq a$. By setting $a \in\left[0, V_{I C}\left(\mu_{1}=h\right)\right]$, it induces either type of executive to implement only profitable projects, $V_{1} \geq 0$. As in either case both types of executives use the same implementation strategy, a change in $a$ leaves the likelihood of selecting a competent executive unaffected. The best the board can do is to induce either type of executive to implement only profitable projects. This can be guaranteed by setting $a=0 .{ }^{22}$

Whether the board wants to discipline the competent executive only (the selection option) or both types of executive (the disciplining option) is described in the next proposition.

Proposition 3 Suppose 'no news is bad news'. If $\lambda<\Pi_{C}-\Pi_{I C}$, the board has two options. It either chooses the selection option by setting $a=\widetilde{V}_{C}(0)$, or it chooses the disciplining option by setting $a=0$. An increase in $\lambda$, or a decrease in $\Pi_{C}-\Pi_{I C}$ or $\rho$ widens the range of parameters for which the board chooses the disciplinig option. The parameter $\gamma$ does not affect the choice of option. If instead $\lambda \geq \Pi_{C}-\Pi_{I C}$, the board's dominant strategy is to choose the disciplining option by setting $a=0$.

Proof: Appendix

As under the retention contract 'no news is good news', the board's choice of $a$ under 'no news is bad news' is a choice between putting emphasis on disciplining or

\footnotetext{
${ }^{22}$ To be precise, the board can choose any $a \in\left[0, V_{I C}\left(\mu_{1}=h\right)\right]$, whence $a=0$ being a weakly dominant strategy, see Lemma 4 . In what follows we will ignore the other weakly dominant strategies $a \in\left(0, V_{I C}\left(\mu_{1}=h\right)\right]$.
} 
selecting. For instance, an increase in benefits $\lambda$ strengthens executives' incentives to distort the implementation decision. Therefore, an increase in $\lambda$ makes the disciplining option more important (choose $a=0$ ). In contrast, the higher is $\Pi_{C}-\Pi_{I C}$, the more important it is that a competent executive keeps office. Consequently, the higher is $\Pi_{C}-\Pi_{I C}$, the more the board would like to emphasize the selection function of the retention contract (choose $a=\widetilde{V}_{C}(0)$ ).

Qualitatively, Proposition 3 only differs from Proposition 2 in the effects of $\gamma$. The reason is that under the retention contract 'no news is good news' an increase in $\gamma$ facilitates disciplining an incumbent. However, under 'no news is bad news', the board can always discipline the incumbent. Consequently, under the latter retention contract, $\gamma$ does not influence the choice between the two options concerning $a$.

\section{The Two Retention Contracts Compared}

Boards of directors perform two main functions. They influence what top executives consider acceptable actions, and they screen incumbents with a view to retaining competent ones and dismissing incompetent ones. We have argued that within a retention contract or norm the board faces a trade-off between increasing the likelihood of selecting a competent executive on the one hand, and weakening executives' incentives to distort the implementation decision on the other hand. Essentially the same trade-off exists when comparing the effectiveness of the two retention norms. The main difference between the two norms is the board's reaction to an executive who has implemented an important project the outcomes of which are not known yet. From a narrow selection point of view, the board's adequate reaction is to keep the executive. As shown in Section 3, it is more likely that a project is implemented by an executive who is competent than incompetent. Thus, a benefit of "no news is good news' is that in case of no news the executive is retained. This improves the expected quality of projects implemented in the second period. However, from a disciplining perspective, the board benefits from announcing and sticking to a 'no news is bad news' norm, as it reduces an executive's incentive to distort the implementation decision.

It is now easy to determine which type of retention norm performs better depending on the value of $\lambda$. For small values of $\lambda$, executives hardly have incentives 
to distort the implementation decision. The implication is that for small values of $\lambda$ the retention contract 'no news is bad news' is relatively unattractive. It scores badly on selecting, while the benefits of disciplining are small. More generally, one can show that if $\lambda$ is smaller than a certain threshold $\lambda<\lambda_{L}$, then the board prefers 'no news is good news' to 'no news is bad news'. The opposite holds for very high values of $\lambda$. Lemma 1 and 2 show that with 'no news is good news' and very high values of $\lambda$, both competent and incompetent executives virtually always implement the project in period 1. Clearly, disciplining is then desired. By choosing 'no news is bad news' with $a=0$ the board assures that only profitable projects are implemented. One can show that if $\lambda$ is sufficiently high $\lambda>\lambda_{H}$, then the board prefers 'no news is bad news' to 'no news is good news'.

For moderate values of $\lambda$, the relative performance of the two retention norms is less clear. All parameters play a role. Numerical analysis suggests that a rise in $\Pi_{C}-\Pi_{I C}$ always makes 'no news is good news' a more attractive choice. This difference in profit is the reason for having a selection procedure before period two. It is therefore quite intuitive that an increase in this difference makes the retention contract focusing on selection relatively more attractive. An increase in $\gamma$, the likelihood with which the value of the project becomes known before the board decides on retention, also makes the choice for 'no news is good news' more appealing. The reason is that an increase in $\gamma$ lowers the cost (distortion of the implementation decision) of the 'no news is good news' retention contract.

Apart from how the parameters of the model affect the choice between the two retention contracts, another feature of the retention contracts is worth emphasizing. In the introduction, we have discussed examples of top executives who were acknowledged as competent, but who were nevertheless dismissed. Our model provides an explanation. First consider the 'no news is good news' retention contract. Suppose that within this contract the board chooses the disciplining option, affecting the implementation decision of either type of executive. Then, as argued in Section 6, a competent executive chooses implementation for a wider range of parameters than an incompetent executive. Consequently, when the board observes that the project outcome falls in this range, it can infer that the executive is competent. Nevertheless, it will dismiss him. The reason is that following a strict retention contract weakens executives' incentives to distort the implementation decision. Occasionally 
dismissing competent executives is the price the board has to pay for discipline. Under the 'no news is bad news' retention contract a similar phenomenon exists. Again, a competent executive chooses implementation for a wider range of parameters than an incompetent one. This result is independent of the choice of the board between only disciplining the competent executive and disciplining either type of executive. Hence, implementation signals competence. Therefore, dismissing, rather than retaining, an executive when a project has been implemented but outcomes remain unobserved makes it quite probable that the dismissed executive is competent.

\section{Conclusion}

Boards of directors have limited information that can be used to discipline and screen the top executives of their companies. In this paper we have analysed a simple model that shows the dilemmas that result. The desire to screen executives to improve the future wellbeing of the organization induces executives to become overly active to show their credentials. The board can counter this tendency by dismissing an executive whose projects are proven to destroy value. Besides, it can decide to replace the incumbent if it knows that a project has been implemented, but its results remain as yet unobserved. Either decision will reduce the temptation to implement loss-generating projects. But unfortunately, if it decides to dismiss the incumbent on either ground, the board can deduce that the expected quality of the incoming executive will be lower than that of the incumbent who is forced to leave. We have shown under what circumstances one retention contract is preferred over another.

Mace (1971) noticed that only in case of repeatedly observed bad performance is an executive ousted. One way of interpreting this finding is that, by and large, the parameter values in the real world are such that boards prefer a "no news is good news" retention norm. After all, if executives identify themselves with the wellbeing of their company, or if it is very hard to find a capable executive that could replace the current one, "no news is good news" is the more adequate norm. There may be other reasons for the pattern observed by Mace. First, note that if the board follows this norm, it does not face a dilemma in case the benefits of a project are still unknown: the incumbent stays and this is best from a screening perspective. For a 
board that does not want to upset amiable relations with the executive, this normgranting the executive the benefit of the doubt - may well be preferred to "no news is bad news". Second, a board that uses a "no news is bad news" contract may induce executives to focus on projects and investments that generate visible results quickly. This short-termism may pose a threat to the long-term viability of the organization. We did not discuss this possibility, but it should not be hard to integrate it into the current set-up. Third, in our modelling approach we see the executive as the agent, and the board as its principal, albeit a badly informed one. Hermalin and Weisbach (1998) argue that it may be better to replace this approach by one in which an executive influences the composition of the board and negotiates about its pay. The better the executive performed in the past, the more leeway he will have. Bebchuk and Fried (2003) argue that a managerial power approach to the relation between a board and an executive should complement the standard principal-agent approach. Again, board members who are selected by the top executive and who enjoy substantial pay and prestige because of their position are unlikely to "rock the boat" and come into action unless some egregious and obvious problem cannot be denied any longer. Future research that aims at integrating retention strategies as used in the current paper and a bargaining or managerial power approach seems to be a worthwhile undertaking. 


\section{Appendix}

Proof of Proposition 2: Proposition 2 consists of two parts. First, it defines a parameter space $\left(V_{I C}^{*}(\lambda) \leq \widehat{V}_{C}\right)$ for which the principal's dominant strategy is to discipline an agent irrespective of his type and a parameter space $\left(V_{I C}^{*}(\lambda)>\widehat{V}_{C}\right)$ for which the principal sometimes chooses the selection option and sometimes the disciplining option. Second, for $V_{I C}^{*}(\lambda)>\widehat{V}_{C}$, the proposition gives the comparative statics results. In the main text the conditions on the parameter space are derived. So, what remains to be proven are the comparative statics results.

To derive the comparative statics results if $V_{I C}^{*}(\lambda)>\widehat{V}_{C}$, we distinguish two cases. First, if $\lambda<\lambda^{*}=\frac{\gamma}{1-\gamma}\left(\Pi_{C}-\Pi_{\rho}\right)$, the principal can fully discipline the competent agent. Second, if $\lambda \geq \lambda^{*}$, the principal can only partially discipline the competent agent.

\section{Comparative statics results for $\lambda<\lambda^{*}$}

To derive the comparative statics results for $\lambda<\lambda^{*}$, we take two steps. First, we determine the principal's expected utility if she chooses the selection option. Next, we determine the principal's expected utility if she chooses the disciplining option. Suppose the principal chooses the selection option and sets $a=V_{C}^{*}(0)$, implying that a competent agent implements the project iff $V_{1}>V_{C}^{*}(0)$ and an incompetent agent implements the project iff $V_{1} \geq V_{I C}^{*}(\lambda)$. Then the principal's expected utility equals

$$
\begin{aligned}
& \Pi_{\rho}-\frac{1}{4 h}\left(\rho\left(V_{C}^{*}(0)\right)^{2}+(1-\rho)\left(V_{I C}^{*}(\lambda)\right)^{2}\right) \\
& +\left[\Pi_{\rho}+\frac{\rho(1-\rho)}{2 h}\left(f+V_{I C}^{*}(\lambda)-V_{C}^{*}(0)\right)\left(\Pi_{C}-\Pi_{I C}\right)\right]
\end{aligned}
$$

Filling in $V_{I C}^{*}(\lambda)$ (see (4)) and $V_{C}^{*}(0)$ (see (3) with $\lambda=0$ ) and rewriting gives

$$
\begin{aligned}
& \Pi_{\rho}-\frac{1-\rho}{4 h}\left(\rho\left(\Pi_{C}-\Pi_{I C}\right)^{2}+\lambda^{2}-2 \rho\left(\Pi_{C}-\Pi_{I C}\right) \lambda\right) \\
& +\left[\Pi_{\rho}+\frac{\rho(1-\rho)}{2 h}\left(f+\left(\Pi_{C}-\Pi_{I C}\right)-\lambda\right)\left(\Pi_{C}-\Pi_{I C}\right)\right]
\end{aligned}
$$

Now suppose the principal chooses the disciplining option and sets $a \in\left[\widehat{V}_{I C}(\lambda), V_{I C}\left(\mu_{1}=h\right)\right]$, implying that a competent agent implements the project iff $V_{1} \geq \widehat{V}_{C}(\lambda)$ and an in- 
competent agent implements the project iff $V_{1} \geq \widehat{V}_{I C}(\lambda)$. Then the expected utility to the principal equals

$$
\begin{aligned}
& \Pi_{\rho}-\frac{1}{4 h}\left(\rho\left(\widehat{V}_{C}(\lambda)\right)^{2}+(1-\rho)\left(\widehat{V}_{I C}(\lambda)\right)^{2}\right) \\
& +\left[\Pi_{\rho}+\frac{\rho(1-\rho)}{2 h}\left(f+(1-\gamma)\left(\widehat{V}_{I C}(\lambda)-\widehat{V}_{C}(\lambda)\right)\right)\left(\Pi_{C}-\Pi_{I C}\right)\right]
\end{aligned}
$$

Filling in $\widehat{V}_{I C}(\lambda)$ (see lemma 2) and $\widehat{V}_{C}(\lambda)$ (see (5)) and rewriting gives

$$
\begin{aligned}
& \Pi_{\rho}-\frac{(1-\gamma)^{2}}{4 h}\left(\rho(1-\rho)\left(\Pi_{C}-\Pi_{I C}\right)^{2}+\lambda^{2}\right) \\
& +\left[\Pi_{\rho}+\frac{\rho(1-\rho)}{2 h}\left(f+(1-\gamma)^{2}\left(\Pi_{C}-\Pi_{I C}\right)\right)\left(\Pi_{C}-\Pi_{I C}\right)\right]
\end{aligned}
$$

Now the choice between the selection option and the disciplining option amounts to a comparison between (10) and (11). The principal chooses the selection option if

$$
(\gamma(2-\gamma)-\rho) \lambda^{2}-\rho(1-\rho) \gamma(2-\gamma)\left(\Pi_{C}-\Pi_{I C}\right)^{2}<0
$$

Notice that inequality (12) always holds if

$$
\gamma(2-\gamma)-\rho \leq 0
$$

Thus if (13) holds, the principal always chooses the selection option. Given $\gamma(2-\gamma)-$ $\rho>0$, then the principal chooses the selection option iff

$$
\lambda<\bar{\lambda}_{1}=\left(\Pi_{C}-\Pi_{I C}\right) \sqrt{\frac{\rho(1-\rho) \gamma(2-\gamma)}{(\gamma(2-\gamma)-\rho)}}
$$

where $\bar{\lambda}_{1}$ is the value of $\lambda$ at which the principal is indifferent between disciplining only the competent agent and disciplining either type of agent.

We are now ready to determine the effect of $\lambda, f, \rho$ and $\gamma$ on the choice between the selection option and the disciplining option.

- An increase in $\lambda$ widens the range of parameters for which the principal chooses to discipline either type of agent. This result follows directly from (14).

- The higher is the parameter $f$, the less attractive is the disciplining option. 
An increase in $f$, has a positive effect on $\bar{\lambda}_{1}$

$$
\frac{d \bar{\lambda}_{1}}{d f}=\frac{d\left(\Pi_{C}-\Pi_{I C}\right)}{d f} \sqrt{\frac{\rho(1-\rho) \gamma(2-\gamma)}{(\gamma(2-\gamma)-\rho)}}
$$

where $\frac{d\left(\Pi_{C}-\Pi_{I C}\right)}{d f}=2(h+p+f)>0$.

- The higher is the parameter $\rho$, the less attractive is the disciplining option. First, note that an increase in $\rho$ widens the range for which the principal always chooses selection $\left(\frac{d}{d \rho}(\gamma(2-\gamma)-\rho)=-1<0\right)$. Second, if $\gamma(2-\gamma)-\rho>0$, an increase in $\rho$, has a positive effect on $\bar{\lambda}_{1}$.

$$
\frac{d \bar{\lambda}_{1}}{d \rho}=\frac{\left(\Pi_{C}-\Pi_{I C}\right) \gamma(2-\gamma)((1-2 \rho)(\gamma(2-\gamma)-\rho)+\rho(1-\rho))}{2(\rho(1-\rho) \gamma(2-\gamma))^{\frac{1}{2}}(\gamma(2-\gamma)-\rho)^{\frac{3}{2}}}>0
$$

To prove that $\frac{d \bar{\lambda}_{1}}{d \rho}>0$, we must show that $t=(1-2 \rho)(\gamma(2-\gamma)-\rho)+$ $\rho(1-\rho)>0$. We can prove that $t>0$ by showing that the lowest possible value of $t$ is positive. The proof consists of two steps. First, we can show that $\frac{d t}{d \rho}=-(2-\gamma) 2 \gamma+\rho<0$. Recall that $\rho<\gamma(2-\gamma)$. Hence, by taking $\rho=\lim _{\varepsilon \downarrow 0}(\gamma(2-\gamma)-\varepsilon)=\gamma(2-\gamma)$ we obtain the lowest value of $t$. Let $t^{\text {min }}$ be this value of $t$. Then $t^{\min }=\gamma\left(6-9 \gamma+4 \gamma^{2}-\gamma^{3}\right)$. The sign of $t^{\text {min }}$ depends on the sign of $t^{\prime}=\left(6-9 \gamma+4 \gamma^{2}-\gamma^{3}\right)$. Taking the derivative with respect to $\gamma$ we get $\frac{d t^{\prime}}{d \gamma}=9+8 \gamma-3 \gamma^{2}<0$, where $0<\gamma<1$. Hence, by taking $\gamma=\lim _{\varepsilon \downarrow 0}(1-\varepsilon)=1$ we find that in the limit the minimum value of $t^{\prime}$ equals 0 . This implies that in the limit the lowest possible value of $t$ is zero. Hence, we can conclude that $\frac{d \bar{\lambda}_{1}}{d \rho}>0$.

- The higher is the parameter $\gamma$, the more attractive is the disciplining option. First, note that an increase in $\gamma$, narrows the range of parameters for which the principal always chooses selection $\left(\frac{d}{d \gamma}(\gamma(2-\gamma)-\rho)=2(1-\gamma)>0\right)$. Second, if $\gamma(2-\gamma)-\rho>0$ an increase in $\gamma$ has a negative effect on $\bar{\lambda}_{1}$.

$$
\frac{d \bar{\lambda}_{1}}{d \gamma}=\frac{-(1-\gamma)(1-\rho) \rho^{2}\left(\Pi_{C}-\Pi_{I C}\right)}{(\gamma(2-\gamma) \rho(1-\rho))^{\frac{1}{2}}(\gamma(2-\gamma)-\rho)^{\frac{3}{2}}}<0
$$




\section{Comparative statics results for $\lambda \geq \lambda^{*}$}

To derive the comparative static results for $\lambda \geq \lambda^{*}$, we again have to compare the principal's expect utility if she chooses the selection option and the principal's expected utility if she chooses the disciplining option. In the previous case we have already determined the expected utility if the principal chooses the disciplining option. So, let us now determine the principal's expected utility if she chooses the selection option. This means that (i) the principal sets $a=\widehat{V}_{C}(\lambda)$, (ii) a competent agent implements the project iff $V_{1} \geq \widehat{V}_{C}(\lambda)$, and (iii) an incompetent agent implements the project iff $V_{1} \geq V_{I C}^{*}(\lambda)$. The principal's expected utility then equals

$$
\begin{aligned}
& \Pi_{\rho}-\frac{1}{4 h}\left(\rho\left(\widehat{V}_{C}(\lambda)\right)^{2}+(1-\rho)\left(V_{I C}^{*}(\lambda)\right)^{2}\right)+ \\
& {\left[\Pi_{\rho}+\frac{\rho(1-\rho)}{2 h}\left(f+V_{I C}^{*}(\lambda)-\widehat{V}_{C}(\lambda)\right)\left(\Pi_{C}-\Pi_{I C}\right)\right]}
\end{aligned}
$$

Filling in the values of $\widehat{V}_{C}(\lambda)$ (see $\left.(5)\right)$ and $V_{I C}^{*}(\lambda)$ (see (4)) and rewriting gives

$$
\begin{aligned}
& \Pi_{\rho}-\frac{1}{4 h}\left(\rho\left(-(1-\gamma)(1-\rho)\left(\Pi_{C}-\Pi_{I C}\right)-(1-\gamma) \lambda\right)^{2}+(1-\rho)\left(\rho\left(\Pi_{C}-\Pi_{I C}\right)-\lambda\right)^{2}\right) \\
& +\left[\Pi_{\rho}+\frac{\rho(1-\rho)}{2 h}\left(f+(1-\gamma(1-\rho))\left(\Pi_{C}-\Pi_{I C}\right)-\gamma \lambda\right)\left(\Pi_{C}-\Pi_{I C}\right)\right]
\end{aligned}
$$

The choice between the selection option and the disciplining option amounts to comparing (15) and (11). The principal chooses the selection option if

$$
\lambda<\bar{\lambda}_{2}=\frac{\left(\Pi_{C}-\Pi_{I C}\right)}{2-\gamma}(\rho(1-\gamma)+\sqrt{\rho(2(1-\gamma)(2-\gamma)+\rho)})
$$

We can now determine the effect of $\lambda, f, \rho$ and $\gamma$ on the choice between selection and disciplining.

- An increase in $\lambda$ widens the range of parameters for which the principal chooses to discipline either type of agent, rather than only disciplining a competent agent. This result follows directly from (16).

- The higher is $f$, the less attractive is the disciplining option. An increase in 
$f$, has a positive effect on $\bar{\lambda}_{2}$.

$$
\frac{d \bar{\lambda}_{2}}{d f}=\frac{d\left(\Pi_{C}-\Pi_{I C}\right)}{d f} \frac{(\rho(1-\gamma)+\sqrt{\rho(2(1-\gamma)(2-\gamma)+\rho)})}{2-\gamma}
$$

where $\frac{d\left(\Pi_{C}-\Pi_{I C}\right)}{d f}=2(h+p+f)>0$.

- The higher is $\rho$, the less attractive is the disciplining option. An increase in $\rho$, has a positive effect on $\bar{\lambda}_{2}$.

$$
\frac{d \bar{\lambda}_{2}}{d \rho}=\frac{\left(\Pi_{C}-\Pi_{I C}\right)}{2-\gamma}\left((1-\gamma)+\frac{1}{2} \frac{2(\rho+(1-\gamma)(2-\gamma))}{\sqrt{\rho(2(1-\gamma)(2-\gamma)+\rho)}}\right)>0
$$

- The higher is $\gamma$, the more attractive is the disciplining option. An increase in $\gamma$ has a negative effect on $\bar{\lambda}_{2}$.

$$
\frac{d \bar{\lambda}_{2}}{d \gamma}=\frac{\left(\Pi_{C}-\Pi_{I C}\right)}{(2-\gamma)^{2}}\left(-\rho+\frac{-(2-\gamma-\rho) \rho}{\sqrt{\rho(2(1-\gamma)(2-\gamma)+\rho)}}\right)<0
$$

Q.E.D.

Proof of proposition 3: Proposition 3 consists of two parts. First, it defines a parameter space $\left(\lambda<\Pi_{C}-\Pi_{I C}\right)$ for which the principal's dominant strategy is to discipline either type of agent and a parameter space $\left(\lambda \geq \Pi_{C}-\Pi_{I C}\right)$ for which the principal can choose between the selection option and the disciplining option. Second, for $\lambda<\Pi_{C}-\Pi_{I C}$, the proposition gives the comparative statics results. First, we derive the conditions on the parameter space. If $\widetilde{V}_{C}(0) \geq \widetilde{V}_{I C}(\lambda)$ (that is $\left.\lambda \geq\left(\Pi_{C}-\Pi_{I C}\right)\right)$, setting $a=\widetilde{V}_{C}(0)$ also affects an incompetent agent's behavior. In this situation disciplining only a competent agent is not a real option. Therefore, the principal's dominant strategy is to discipline either type of agent by setting $a \in\left[0, V_{I C}\left(\mu_{1}=h\right)\right]$. If $\lambda<\left(\Pi_{C}-\Pi_{I C}\right)$, then the principal can choose to discipline only the competent agent or she can discipline either type of agent. What remains to be proven are the comparative statics results in the last situation.

To derive the comparative statics results we take two steps. First, we determine the expected utility if the principal chooses the selection option. Second, we determine the principals expected utility if she chooses to discipline either type of agent.

Suppose the principal chooses the selection option and sets $a=\widetilde{V}_{C}(0)$, implying 
that a competent agent implements the project iff $V_{1} \geq \widetilde{V}_{C}(0)$ and an incompetent agent implements the project iff $V_{1} \geq \widetilde{V}_{I C}(\lambda)$. Then the principal's expected utility equals

$$
\begin{aligned}
& \Pi_{\rho}-\frac{1}{4 h}\left(\rho\left(\widetilde{V}_{C}(0)\right)^{2}+(1-\rho)\left(\widetilde{V}_{I C}(\lambda)\right)^{2}\right) \\
& +\left[\Pi_{\rho}+\frac{\gamma \rho(1-\rho)}{2 h}\left(f+\widetilde{V}_{I C}(\lambda)-\widetilde{V}_{C}(0)\right)\left(\Pi_{C}-\Pi_{I C}\right)\right]
\end{aligned}
$$

Filling in $\widetilde{V}_{I C}(\lambda)$ (see (10)) and $\widetilde{V}_{C}(0)$ (see (9) with $\lambda=0$ ) and rewriting gives the following expression

$$
\begin{aligned}
& \Pi_{\rho}-\frac{(1-\rho) \gamma^{2}}{4 h}\left(\rho\left(\Pi_{C}-\Pi_{I C}\right)^{2}+\lambda^{2}-2 \rho\left(\Pi_{C}-\Pi_{I C}\right) \lambda\right) \\
& +\left[\Pi_{\rho}+\frac{\gamma^{2} \rho(1-\rho)}{2 h}\left(f+\left(\Pi_{C}-\Pi_{I C}\right)-\lambda\right)\left(\Pi_{C}-\Pi_{I C}\right)\right]
\end{aligned}
$$

Now suppose the principal chooses the selection option and sets $a \in\left[0, V_{I C}\left(\mu_{1}=h\right)\right]$, implying that an agent implements the project iff $V_{1} \geq 0$. Then the principal's expected utility equals

$$
\Pi_{\rho}+\left[\Pi_{\rho}+\frac{\gamma \rho(1-\rho)}{2 h} f\left(\Pi_{C}-\Pi_{I C}\right)\right]
$$

Now the choice between the selection option and the disciplining option can be analyzed by comparing (17) and (18). The principal prefers the selection option to the disciplining option if

$$
\begin{aligned}
\lambda^{2} & <\rho\left(\Pi_{C}-\Pi_{I C}\right)^{2} \\
\lambda & <\bar{\lambda}_{3}=\sqrt{\rho}\left(\Pi_{C}-\Pi_{I C}\right)
\end{aligned}
$$

where $\bar{\lambda}_{3}$ is the value of $\lambda$ for which the principal is indifferent between the selection option and the disciplining option.

Now we can determine how the parameters $\lambda, f, \rho$ and $\gamma$ affect the choice between selection and disciplining.

- An increase in $\lambda$, widens the range of parameters for which the principal chooses to discipline either type of agent. This result follows directly from 
(19).

- An increase in $f$, narrows the range of parameters for which the principal chooses to discipline either type of agent. An increase in $f$ has a positive effect on $\bar{\lambda}_{3}$

$$
\frac{d \bar{\lambda}_{3}}{d f}=\frac{d\left(\Pi_{C}-\Pi_{I C}\right)}{d f} \sqrt{\rho}
$$

where $\frac{d\left(\Pi_{C}-\Pi_{I C}\right)}{d f}>0$.

- The higher is $\rho$, the smaller is the range for which the principal chooses to discipline either type of agent and the larger is the range for which the principal chooses to discipline only the competent agent. An increase in $\rho$ has a positive effect on $\bar{\lambda}_{3}$

$$
\frac{d \bar{\lambda}_{3}}{d \rho}=\frac{\left(\Pi_{C}-\Pi_{I C}\right)}{2 \sqrt{\rho}}>0
$$

- The parameter $\gamma$ has no effect on the choice between disciplining the competent agent only or disciplining either type of agent. An increase in $\gamma$ has no effect on $\bar{\lambda}_{3}\left(\frac{d \bar{\lambda}_{3}}{d \gamma}=0\right)$.

Q.E.D. 


\section{References}

[1] Aggarwal, R. K. and A. A. Samwick (2003), Empire-builders and Shirkers: Investment, Firm Performance, and Managerial Incentives. working paper.

[2] Barro, R. (1973), The Control of Politicians: An Economic Model, Public Choice, 14, 19-42.

[3] Baumol, W. J. (1959), Business Behavior, Value and Growth. MacMillan, New York.

[4] Bebchuk, L. A. and J. M. Fried (2003), Executive Compensation as an Agency Problem, Journal of Economic Perspectives, 17 (3), 71-92.

[5] Berganza, J.C. (2000), Two roles for elections: Disciplining the incumbent and selecting a competent candidate, Public Choice, 105, 165-193.

[6] Besley, T. (2004), Political Agency and Accountability in: Besley, T., Principled Agents? The Political Economy of Good Government, Chapter 3, mimeo.

[7] Borokovich, K. A., R. Parrino, and T. Trapani (1996), Outside Directors and CEO Selection, Journal of Financial and Quantitative Analysis, 31 (3), 337-355.

[8] Brickley, J. A. (2003), Empirical Research on CEO Turnover and FirmPerformance: A Discussion, Journal of Accounting \& Economics, 36, 227-233.

[9] Demb, A. and F.-F. Neubauer (1992), The Corporate Board: Confronting the Paradoxes. Oxford University Press, New York etc.

[10] Dittmann, I. and E. Maug (forthcoming), Lower Salaries and No Options? On the Optimal Structure of Executive Pay, The Journal of Finance.

[11] The Economist (2005), Running for Cover (Dec 20th issue).

[12] The Economist (2006), Egg on his Face (Jan 5th issue).

[13] Ferejohn, J. (1986), Incumbent performance and electoral control, Public Choice, 50, 5-25. 
[14] Graziano, C. and A. Luporini (2003), Board Efficiency and Internal Corporate Control Mechanisms, Journal of Economics $\&$ Management Strategy, 12 (4), 495-530.

[15] Hall, B. J. and J. B. Liebman (1998), Are CEOs Really Paid Like Bureaucrats?, The Quarterly Journal of Economics, 113 (3), 653-691.

[16] Hermalin, B. E. (2005), Trends in Corporate Governance, The Journal of Finance, 60 (5), 2351-2384.

[17] Hermalin, B. E. and Weisbach, M. S. (1998), Endogenously chosen boards of directors and their monitoring of the CEO, American Economic Review, 88 (1), 96-118.

[18] Hermalin, B. E. and Weisbach, M. S. (2003), Boards of Directors as an Endogenously-Determined Institution: A Survey of the Economic Evidence, FRBNY Economic Policy Review, 9, 7-26.

[19] Jensen, M. C. (1986), Agency Costs of Free Cash Flow, Corporate Finance, and Takeover, American Economic Review, 76 (2), 323-329.

[20] Kaplan, N. (1994), Top Executive Rewards and Firm Performance: A Comparison of Japan and the United States, Journal of Political Economy, 102 (3), 510-546.

[21] Lorsch, J. and E. MacIver (1989), Pawns or Potentates. The Reality of America's Corporate Boards. Harvard Business School Press, Boston, Massachusetts.

[22] Mace, M.L. (1971), Directors: Myth and Reality, Harvard University Press, Boston.

[23] Marris, R. (1964), The Economic Theory of 'Managerial' Capitalism. MacMillan \& Co, London.

[24] Persson, T., Tabellini, G (2000), Political Economics: Explaining Economic Policy, The MIT Press, Cambridge, Massachusetts - London, England.

[25] Stiles, Ph. and Taylor, B. (2001), Boards at work: how directors view their roles and responsibilities, Oxford: Oxford University Press. 
[26] Stulz, R. M. (1990), Managerial Discretion and Optimal Financing Policies, Journal of Financial Economics, 26 (1), 3-27.

[27] Tirole, J. (2006), The Theory of Corporate Finance, Princeton University Press, Princeton, New Jersey.

[28] Warner, J. B., R. L. Watts, and Karen H. Wruck (1988), Stock Prices and Top Management Changes, Journal of Financial Economics, 20, 461-492.

[29] Weisbach, M. (1988), Outside Directors and CEO Turnover, Journal of Financial Economics, 20, 431-460.

[30] Williamson, O. (1974), Economics of Discretionary Behaviour: Managerial Objectives in a Theory of the Firm. Kershaw Publishing, London. 